Research Paper:

\title{
Study the Relationship Among Early Maladaptive Schemas, Alexithymia and Ego Defensive Styles of Students at Azad and Payame Noor Universities in Shahindej
}

\author{
Surur Ezatian ${ }^{1^{*}}$ (D), Mohammad Ahmadpanah² (D)
}

1. Department of Clinical Psychology, Bukan Branch, Islamic Azad University, Bukan, Iran.

2. Department of Psychiatry, School of Medicine, Hamadan University of Medical Sciences, Hamadan, Iran.

\begin{tabular}{|l|l}
$\begin{array}{l}\text { Use vour device to san } \\
\text { and read the article online }\end{array}$ & $\begin{array}{l}\text { Citation Ezatian S, Ahmadpanah M. Study the Relationship Among Early Maladaptive Schemas, Alexithymia and Ego Defensive } \\
\text { Styles of Students at Azad and Payame Noor Universities in Shahindej. Avicenna J of Neuropsychophysiology. 2017; 4(3):87-94. } \\
\text { http://dx.doi.org/10.32598/ajnpp.4.3.87 }\end{array}$ \\
dol'http://dx.doi.org/10.32598/ajnpp.4.3.87
\end{tabular}

\section{(c) (1) (8)}

Article info:

Received: 23 Feb 2017

Accepted: 28 Jun 2018

Available Online: 01 Aug 2017

Keywords:

Early maladaptive schemas, Alexithymia, Ego defensive styles, Azad and Payame Noor University

\begin{abstract}
A B S T R A C T
Background: Ego-defense mechanisms are automated ordering processes to reduce cognitive abnormal and contort perceptions of threatening events. Defense mechanisms are divided into different groups in terms of their relationship with psychosocial maturity. In the psychoanalytic system, each mental disturbance is related to certain incompatible defensive mechanisms. Early maladaptive schemas are emotional and cognitive patterns which are formed since childhood and duplicated across life. Alexithymia is the inability to cognitively process emotional information and emotion regulation. Individuals with alexithymia overexpress normal body massages, misinterpret symptoms of emotional arousal, and show emotional distress through physical complaints. Therefore, alexithymia is a multifaceted structure.
\end{abstract}

Objectives: To examined the relationship among early maladaptive schemas, alexithymia and ego-defensive styles of students in two universities of Iran.

Materials and Methods: This correlational study was conducted on students of Azad and Payame Noor universities in Shahindej City, West Azerbaijan Province, Iran in 2017. The study population included all students of Azad and Payame Noor universities in this city. Of them, a total of 306 students were chosen by the multi-stage cluster sampling method. Three questionnaires were used for data collection. These questionnaires were the early maladaptive schemas questionnaire, ego-defensive styles questionnaire, and alexithymia questionnaires. The collected data were analyzed in SPSS V. 20.

Results: There is an inverse relationship between early maladaptive schemas and ego-defensive styles $(0.023)$. There is an inverse relationship between early maladaptive schemas and alexithymia (0.016). Alexithymia of male and female students was different $(0.000)$. But the early maladaptive schemas and the ego defense styles are the same (0.404). Early maladaptive schemas and the defensive styles of university students are different. But the alexithymia was the same (0.753).

Conclusion: Our findings indicate that early maladaptive schemas can act as the foundation of emotional and behavioral tendencies and defensive styles in students.

* Corresponding Author:

Surur Ezatian, MSc.

Address: Department of Clinical Psychology, Bukan Branch, Islamic Azad University, Bukan, Iran.

E-mail: surur.ezatian@gmail.com 


\section{Introduction}

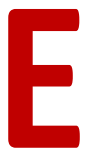

go-defense mechanisms are known as automated ordering processes that act to reduce cognitive abnormal and contort perceptions of threatening events, trying to downgrade abrupt changes in the internal and external reality. Subjectively and objectively, defense mechanisms are divided into different groups that are related to the level of defense action. The efforts of defense mechanisms to reduce inhibiting thoughts or, at least, prevent them from stabilization of attributes and habits lead to the formation of personality [1].

The defense mechanisms are adjusted in terms of their relationship with psychosocial maturity and psychological harm in a hierarchical order. The defense mechanisms which are responsible for protecting people may be usual or unusual, efficient or useless [2]. In this regard, Andrews et al. reported 20 defense mechanisms [3]. In the psychoanalytic system, each mental disturbance is related with certain incompatible defensive mechanisms which play a key role in psychological health. Several studies have supported this assumption, and research has shown that the mental and physical health of the people is related to their defense mechanisms $[4,5]$.

According to Young, however, those who have preexisting maladaptive beliefs, show maladaptive strategies that may make their schemas permanent and irrevocable. Early maladaptive schemas are emotional and cognitive patterns which are formed since childhood and duplicated across life. They may be composed of emotional memories of pain, tragedies, fear, abuse, neglect, safety needs, abandonment, or lack of normal human affection in general. Early maladaptive schemas can also include bodily sensations related to such emotional memories. Early Maladaptive Schema (EMS) can be classified in different ways. Young and colleagues classified $18 \mathrm{EMS}$ in two great subcategories and further into five areas. According to Young and colleagues, the exact number of EMS is not constant [6]. Another variable that is directly related to EMS is alexithymia.

Alexithymia is the inability to cognitively process of emotional information and emotion regulation. Individuals with alexithymia magnify normal body massages, misinterpreting physical symptoms of emotional arousal, expressing emotional distress through physical complaints, and seeking therapies for symptom relief. Therefore, alexithymia as a multifaceted structure is characterized by the difficulty in identifying emotions, describing emotions, and objective thinking [2]. Severa studies have been conducted on the field of early maladaptive schemas, defensive mechanisms, and alexithymia, including the following research studies.

Zadmohsen and Seraj Khorrami investigated the relationship between body image worries, early maladaptive schemas, and alexithymia with social anxiety among female students of Islamic Azad University. Their findings showed a relationship between body image worries, early maladaptive schemas, and alexithymia with social anxiety. Also, regression analysis showed that body image worries, early maladaptive schemas, and alexithymia could predict social anxiety [7].

Hemmati-Sabet et al. studied the effectiveness of schema therapy in reducing aggression and social anxiety in boys aged 17-18 years old in Hamadan. The results showed that schema therapy was effective in reducing aggression and social anxiety in adolescents aged 17-18 years old in Hamedan [8]. Farzaneh et al. conducted a study on the relationship between early maladaptive schemes, emotions, and alexithymia with drug addiction. Their findings indicated a relationship between EMS, feelings, and alexithymia with drug addiction prevalence $(P<0.01)$. Also, there was a significant relationship between early maladaptive schemes and the readiness for addiction $(P<0.01)$. [9].

Ghadiri Sourman Abadi and colleagues investigated the relationship between emotional alexithymia and maladaptive schemas among Tabriz University students. The results showed a significant positive relationship between emotional alexithymia and EMS and excessive hearing loss. Also, the regression analysis showed that self-regulation and overlapping areas of activity were emotional predictors [10]. Regarding what was discussed, this study aims to determine the relationship between EMS with alexithymia and ego-defensive styles among the students of Azad and Payame Noor universities in Shahindej City, Iran.

\section{Materials and Methods}

\section{Research design and sampling method}

This was a correlational study and was conducted on students of Azad and Payame Noor universities in Shahindej City, West Azerbaijan Province, Iran in 2017. The multi-stage cluster sampling method was used for choosing study samples from the two universities proportional to the number of students in each university. The study sample size was recruited from 1500 students 
during one semester considering the inclusion and exclusion criteria.

\section{Study tools}

The demographic information questionnaire, standard ego defense styles questionnaire, Toronto Aexithymia Scale (TAS-20), and early maladaptive schemas of Young (short form) were used to collect information. Ego defense styles questionnaire was designed by Andrews et al. [11]. This scale has 40 items. It examines 20 defense mechanisms in three levels of immature, mature, and neurotic styles [3]. This questionnaire was also examined and standardized by Heidari Nasab [12] in Iran. The reliability and validity of the questionnaire were also evaluated based on the correlation of each statement with a related mechanism. The reliability of this scale for the whole questionnaire was 0.84 [12]. In this research, its reliability was found 0.78 based on the Cronbach alpha value.

Toronto Aexithymia Scale (TAS-20) was developed by Taylor in 1986, and revised in 1994 by Bagby, Parker, and Taylor [12]. This scale consists of 20 items in three subscales of difficulty in recognizing emotions ( 7 items), difficulty in describing emotions (5 items), and objective thinking (8 items). Ghorbani et al. calculated the alpha values of this scale in an Iranian sample as 0.44 for the difficulty in detecting emotions, 0.61 for the difficulty in describing emotions, and 0.50 for objective thinking. In this study, the reliability was found 0.81 by using the Cronbach alpha value. Early Maladaptive Schemas Young's Inventory (short form) was developed by Young et al. [13]. The short form of the questionnaire has 75 items that measure 15 early maladaptive schemas. In this research, the reliability was found 0.84 using the Cronbach alpha coefficient.

\section{Study analysis}

The collected data were analyzed with descriptive statistics and the Pearson correlation coefficients in SPSS 20.

\section{Results}

According to the cluster sampling method, 306 students were selected as the statistical sample. The demographic features of the students are presented in Table 1. As shown in Table 2, the mean values for maladaptive components are as follows: emotional deprivation; 16.73, abandonment/instability; 14.85, mistrust/abuse; 15.76, isolation/alienation; 13.32, defectiveness/shame; 15.81, failure; 9.48, dependence/ incompetence; 11.03 , vulnerability to harm or illness; 16.3 , enmeshment/undeveloped self; 14.94 , subjugation; 18.99, self-sacrifice; 15.64, emotional inhibition; 15.91, unrelenting standards; 14.70 , approval-seeking/ recognition-seeking; 13.92, and insufficient self-control and/or self-discipline; 11.77. As shown in Table 2, the mean scores were 16.54 in mature, 54.62 in immature, and 29.49 in neurotic types. As shown in Table 3, the mean value for difficulty in recognizing emotions was 19.96, for difficulty in describing feelings was 17.66 and for objective thinking was 23.14 (Table 4).

\section{Hypotheses}

1. There is a positive relationship between early maladaptive schemas and the alexithymia among the university students. As the significance level is less than 0.05 , there is a significant and inverse relationship between the early maladaptive schemas and emotional alexithymia (Table 5).

2. There is a significant relationship between the early maladaptive schemas with ego defensive styles among the university students. According to Table 6, there is a significant and negative relationship between early maladaptive schemas and ego-defensive styles.

3. There is a significant difference between the male and female students regarding early maladaptive schemas, alexithymia, and ego-defensive styles. According to Table 7, the significance level for the difference between male and female students regarding the early maladap-

Table 1. Sample frequency by gender

\begin{tabular}{ccc}
\hline Students & $\mathbf{n}$ & \% \\
\hline Female & 220 & 72.2 \\
Male & 86 & 27.8 \\
Total & 306 & 100 \\
\hline
\end{tabular}


Table 2. Descriptive indexes of sample for maladaptive schemas

\begin{tabular}{|c|c|}
\hline Schemas & Mean $\pm S D$ \\
\hline Emotional deprivation & $16.73 \pm 3.78$ \\
\hline Abandonment/instability & $14.85 \pm 5.73$ \\
\hline Mistrust/abuse & $15.76 \pm 4.61$ \\
\hline Isolation/alienation & $13.32 \pm 4.58$ \\
\hline Defectiveness/shame & $15.81 \pm 6.11$ \\
\hline Failure & $9.48 \pm 3.28$ \\
\hline Dependence/incompetence & $11.03 \pm 3.37$ \\
\hline Vulnerability to harm or illness & $16.3 \pm 3.34$ \\
\hline Enmeshment/undeveloped self & $14.94 \pm 3.86$ \\
\hline Subjugation & $18.99 \pm 7.48$ \\
\hline Self-sacrifice & $15.64 \pm 6.83$ \\
\hline Emotional inhibition & $15.91 \pm 6.38$ \\
\hline Unrelenting standards & $14.70 \pm 5.55$ \\
\hline Approval-seeking/recognition-seeking & $13.92 \pm 5.71$ \\
\hline Isufficient self-control and/or self-discipline & $11.77 \pm 4.10$ \\
\hline
\end{tabular}

Table 3. Descriptive Indexes of sample for defensive mechanisms

AJNPP

\begin{tabular}{cc}
\hline Variables & Mean \pm SD \\
\hline Mature & $16.54 \pm 3.91$ \\
Immature & $54.62 \pm 30.01$ \\
Neurotic & $29.49 \pm 15.21$ \\
\hline
\end{tabular}

tive schemas was 0.773 . Therefore, the early maladaptive schemas of female and male students are the same.

According to Table 8, the significance level for the difference between male and female students regarding the alexithymia is 0.000 , which is less than 0.05 . There- fore, male and female students' alexithymia is different. According to the Table 8 , the significance level for the difference between male and female students regarding ego-defensive styles is 0.440 , which is more than 0.05 . As a result, there is no significant difference between male and female students regarding ego-defensive styles.

Table 4. Descriptive indexes of experimental group in emotional alexithymia

\begin{tabular}{cc}
\hline Variables & Mean \pm SD \\
\hline Difficulty in recognizing emotions & $19.96 \pm 5.58$ \\
\hline Difficulty in describing emotions & $17.66 \pm 4.58$ \\
\hline Objective thinking & $23.14 \pm 10.16$ \\
\hline
\end{tabular}


Table 5. Correlation between early maladaptive schemas and Emotional Alexithymia

\begin{tabular}{lcr}
\hline & Variables & Emotional Alexithymia \\
\hline Early maladaptive schemas & The Pearson correlation coefficient & -0.139 \\
& $\mathrm{P}$ & 0.016 \\
306
\end{tabular}

Table 6. Correlation between early maladaptive schemas and ego defensive styles

\begin{tabular}{lcc}
\hline & Variables & Ego-Defensive Styles \\
\hline & The Pearson correlation coefficient & -0.112 \\
Early maladaptive schemas & $\mathrm{P}$ & 0.023 \\
& $\mathrm{n}$ & 306 \\
\hline
\end{tabular}

AJNPP

Table 7. T-test for early maladaptive schemas, emotional alexithymia and ego defensive styles in male and female students

\begin{tabular}{|c|c|c|c|c|}
\hline Variables & Subjects & $\mathbf{T}$ & df & Sig. \\
\hline & Male & & & \\
\hline \multirow[t]{2}{*}{ Early maladaptive schemas } & & 0.315 & 304 & 0.753 \\
\hline & Female & & & \\
\hline \multirow{3}{*}{ Alexithymia } & Male & & & \\
\hline & & 4.835 & 304 & 0.000 \\
\hline & Female & & & \\
\hline \multirow{3}{*}{ Ego defensive styles } & Male & & & \\
\hline & & 0.836 & 304 & 0.404 \\
\hline & Female & & & \\
\hline
\end{tabular}

AJNPP

4. There is a significant difference between Azad and Payam Noor university students regarding the early maladaptive schemas, alexithymia, and ego-defensive styles. According to the Table 8 , the significance level obtained for the difference between the early maladaptive schemas between students of Azad and Payame
Noor universities was 0.018 . Therefore, there is a significant difference between the early maladaptive schemas of the students of Azad and Payame Noor universities.

According to the Table 8, the significance level obtained for the difference between the students of Azad

Table 8. T-test for EMS, emotional alexithymia and ego defensive styles between Azad and Payamenoor University students

\begin{tabular}{|c|c|c|c|c|}
\hline Variables & Subjects & $\mathbf{T}$ & df & Sig. \\
\hline & Azad & & & \\
\hline \multirow[t]{2}{*}{ Early maladaptive schemas } & & 2.14 & 304 & 0.018 \\
\hline & Payame Noor & & & \\
\hline & Azad & & & \\
\hline \multirow[t]{2}{*}{ Alexithymia } & & 0.267 & 304 & 0.19 \\
\hline & Payame Noor & & & \\
\hline \multirow{3}{*}{ Alexithymia } & Azad & & & \\
\hline & & 1.98 & 304 & 0.024 \\
\hline & Payame Noor & & & \\
\hline
\end{tabular}


and Payame Noor universities regarding the alexithymia was 0.19 . Therefore, there is no significant difference between the students' alexithymia of two universities. According to the Table 8, the significance level for the difference between students of Azad and Payame Noor universities regarding ego-defensive styles was 0.024, which is less than 0.05 . Therefore, there is a significant difference between the students of Azad and Payame Noor universities regarding ego-defensive styles.

\section{Discussion}

The purpose of this study was to investigate the relationship between EMS, alexithymia, and ego-defensive styles among the students of Azad and Payame Noor universities in Shahindej City, Iran. The findings showed a positive relationship between EMS, alexithymia, and ego-defensive styles among students of Azad and Payamenoor universities. This finding is consistent with the findings of Ghadiri Surman Abadi and colleagues (2015).

In explaining this similarity, it can be said that people who have early maladaptive beliefs can have difficulty in describing their emotions and thus their schemas become permanent and irreversible. Schemas are created because of the lack of satisfaction of the basic emotional needs in childhood and act as a filter for proving or confirming childhood experiences. For this reason, negative schemas in people with problematic childhood experiences cause a lot of negative emotions and impose a negative view of life events. When early maladaptive schemes are activated, they do not directly result in a specific disorder, but increase the vulnerability of the infected person, so the vulnerable person tries to show certain mechanisms against the disorders that have come to pass.

The male and female students' alexithymia is different. However, there is no significant difference between male and female students regarding early maladaptive schemas and defensive styles. This finding is inconsistent with the findings of Abbasi et al. In explaining this discrepancy, it can be said that emotional alexithymia in men is generally rooted in biological factors, while in women, this phenomenon appears as a result of psychological experiences.

Men tend to show more pragmatic behaviors when challenged with emotions and difficulties. Thus, it can be said that these results support the effect of psychosocial and cultural factors on the gender differences in emotional alexithymia. As a result, we can say that our study sample is more than traditional folk stereotypes, considering men's attributes. In addition, people with emotional alexithymia have characteristics such as the difficulty in processing emotional information, difficulty in understanding facial expressions, and less capacity for empathy. This will result in major problems in interpersonal relationships of these people (because of their indifference and indifference to others).

There is a significant difference between the early maladaptive schemas and ego-defensive styles among students of Azad and Payame Noor universities. But alexithymia was the same in both students. In explaining this finding, it can be said that early maladaptive schemas will continue to affect people on the path of life, and will affect the relationship between students at the university and in the classrooms. One of the limitations of this study is related to the statistical sample confined to the students of Islamic Azad University and Payame Noor University in Shahindej City, which could limit the generalizations of the findings. In addition, the limits of using the questionnaire as the only study tools were also present.

According to research findings, we suggest that parents be trained to develop their children's confidence in their childhood and avoid excessive care. Students should receive training on their defensive styles to better cope with and even change their negative emotions and incompatible schemas. It is suggested that measures be taken to teach students to identify the type of their prevalent maladaptive schemas. We also suggest that studying the variables of research in both universities will allow the study of the outbreak to make students more aware of themselves.

\section{Conclusion}

There was a significant difference between the early maladaptive schemas and ego-defensive styles. Accord ing to the obtained results and other similar studies, early maladaptive schemas can act as the foundation of emotional and behavioral tendencies and defensive styles in university students.

\section{Ethical Considerations}

\section{Compliance with ethical guidelines}

This research was approved by the Ethics Committee of the Islamic Azad University of Bukan Branch and written informed consents were taken from the students or legal staff of universities. 


\section{Funding}

The present paper was extracted from the MSc. thesis of the first author, in Department of Clinical Psychology, Bukan Branch, Islamic Azad University.

\section{Authors contributions}

All authors contributed in preparing this article.

\section{Conflict of interest}

The authors declared no conflict of interest.

\section{Acknowledgements}

The authors would like to thank students of Azad and Payame Noor universities of Shahindej.

\section{References}

[1] Ahadi B, Sotuadeh MB, Habibi Y. [The comparison of psychological well-being and defense mechanisms in stuttereing and non stuttering students (Persian)]. Journal of School Psychology. 2013; 1(4):6-22.

[2] Besharat MA. [Relation of alexithymia with ego defense styles (Persian)]. Journal of Fundamentals of Mental Health. 2008; 10(39):181-90.

[3] Besharat MA, Mohammadi Hosseininezhad E, Gholamali Lavasani $M$. [The mediating role of cognitive emotion regulation strategies on the relationship between alexithymia, anger and anger rumination with ego defense styles (Persian)]. Contemporary Psychology. 2015; 9(2):29-48.

[4] Bond M, Perry JC. Long-term changes in defense styles with psychodynamic psychotherapy for depressive, anxiety, and personality disorders. American Journal of Psychiatry. 2004; 161(9):1665-71. [DOI:10.1176/appi.ajp.161.9.1665] [PMID]

[5] Ahmadi M, Najafi M, Hosseini Almadani SA, Ashoori, A. [Comparison of defensive styles and personality traits in addicted and normal individuals (Persian)]. Quarterly Journal of Research on Addiction. 2012; 6(23):39-51.

[6] Young JE, Klosko JS, Weishaar ME. Schema therapy: A practitioner's guide. New York: Guilford Press; 2003.

[7] Zadhasan Z, Seraj Khorrami N. [Correlation between body image worries, early maladaptive schemas and social anxiety in female students of Islamic Azad University (Persian)]. Journal of Social Psychology. 2017; 10(38):61-80.

[8] Hemmati Sabet V, Rohani Shahrestani N, Hemmati Sabet A, Ahmadpanah $M$. [The effectiveness of schema therapy in reducing aggression and social anxiety in adolescents of Hamadan City aged 17 to 18 years (Persian)]. Shenakht Journal of Psychology and Psychiatry. 2016; 3(2):82-93.

[9] Farzaneh M, Mazhab Yousefi A, Ghanbari Hashemabadi BA. [Investigating the relationship between maladaptive schemas, excitement and alexithymia with addiction prevalence (Persian)]. Paper presented at: the $1^{\text {st }}$ International Congress of Comprehensive Psychology in Iran. 17 February 2016; Webynar.

[10] Ghadiri Sourman Abadi F, Khoshkam A, Ghadiri Sourman Abadi F [An Investigation of the relationship between emotional neurotic and early maladaptive schemes in Tabriz university students (Persian)]. Paper presented at: The $1^{\text {st }}$ Scientific Conference on Psychology and Social Harm. 5 May 2015; Tehran, Iran.

[11] Andrews G, Singh M, Bond M. The Defense Style Questionnaire. Journal of Nervous and Mental Disease. 1993; 181(4):246-56. [DOI:10.1097/00005053-199304000-00006]

[12] Heidari Naseb L, Mansoor M, Azad Fallah P, Shairi MR. [Validity and reliability of Defense Style Questionnaire in Iranian samples (Persian)]. Daneshvar Raftar. 2007; 14(22):11-26.

[13] Jazayeri SM, Vatankhah HR, Badiei MM. [The relationship between defense styles and early maladaptive schemas with resilience in boy students of high school in Tehran city (Persian)]. Journal of Thought \& Behavior in Clinical Psychology. 2014; 8(30):7-16 
This Page Intentionally Left Blank 